\title{
Preparation of amino-functionalized mesoporous silica (MCM-41) for Nitrate anion adsorption from aqueous solution
}

\author{
Anaam A. Sabri ${ }^{1}$, and Noor S. Abbood ${ }^{2, *}$ \\ ${ }^{1}$ Department of Chemical Engineering, University of Technology, Baghdad, Iraq, aaksabri@yahoo.com \\ ${ }^{2}$ Department of Chemical Engineering, University of Technology, Baghdad, Iraq, eng_noorsalah@yahoo.com \\ *Corresponding author: Noor S. Abbood, email: eng_noorsalah@yahoo.com \\ ublished online: 30 June 2019
}

Abstract-In this study, mesoporous silica MCM-41 material was synthesized using simple method at room temperature, and then loaded it with amine group by grafting method. MCM-41 was characterized by means of atomic force microscopy (AFM), X-ray diffraction (XRD), BET surface area; Thermal Gravimetric Analysis (TGA) and Fourier transform infrared (FTIR) spectroscopy. Then the ability of MCM-41 as adsorbents to treat NO3 anion as inorganic pollutant from synthetic wastewater was investigated. Batch adsorption was employed to determine the effects of initial concentration $(25-150 \mathrm{mg} / \mathrm{L}), \mathrm{pH}(2-11)$, temperature $(297,313,333 \mathrm{~K})$, adsorbent dose $(0.1-2 \mathrm{~g})$, and contact time $(0-140 \mathrm{~min})$. The results indicated that the kinetic data for nitrate anion adsorption with MCM-41 was fitted well with the pseudo-second-order kinetic model $(\mathrm{R} 2=1)$. It was found that the Freundlich adsorption isotherm model for nitrate anion had the best fit with the experimental data. Various adsorbents (activated carbon, SBA-15, MCM-48) have been utilized to investigate their ability to remove nitrate anion and the results show that MCM-48 could be used to remove NO3 better than other adsorbents.

Keywords- NH2-MCM-41, Adsorption, batch study.

\section{Introduction}

Since years, a few distinct parts of the world have been confronting the issue of nitrogen contamination in the earth. Since nitrate is the most

stable type of nitrogen species in water. Nitrate together with phosphorus, the nearness of high centralizations of nitrate in ground and surface water can quicken the eutrophication. Eutrophication is the intemperate supplement improvement of streams and lakes fortifying the development of green growth and established amphibian plants. Besides, with the expansion of high centralization of nitrate and phosphorus in water, the disintegrated oxygen tends to diminish. Thus it would influence contrarily oceanic living beings' life. The Maximum Acceptable Concentration (MAC) for nitratenitrogen in Iraqi drinking water has been built up as $(25$ 45) $\mathrm{mg}$ N-NO3-/L (Central Organization for Standardization and Quality Control, 2012). Numerous conventional techniques have been connected to the expulsion of nitrate from wastewater. These strategies incorporate organic de-nitrification forms $[1,9]$, synthetic procedures [5] and physical operation [10]. In any case, these strategies are costly, create expanded volumes of slop and require unpredictable and strict control of the working conditions [6]. Expulsion of nitrate by adsorption strategy has pulled in much consideration. Adsorption systems are simple and temperate operations. They produce little slime and permit nitrate recuperation [3]. Moreover, the average properties of meso-organized materials including uniform mesopores and high surface area were observed to be great resources for the adsorptive expulsion of nitrate from water [14, 24]. In perspective of above actualities and in a nonstop mission for high limit, specific, viable and regenerable adsorbents, the present work is planned to orchestrate MCM-41 functionalized with ammonium gatherings and to examine its capacity to expel nitrate from water and wastewater in a research facility scale. 


\section{Experimental Work}

\subsection{Chemicals}

Sodium hydroxide $(\mathrm{NaOH}) \quad 99 \%$ purity, tetraethyl orthosilicate (TEOS) 98\% purity, hydrochloric acid $(\mathrm{HCl})$ $37 \%$ purity, toluene (C6H5-CH3) 98\% purity, cetyltrimethylammonium bromide (CTAB) 98\% purity, ethanol(C2H5OH),3aminopropyltriethoxysilane (APTES) 98\% purity, ammonia solution $(\mathrm{NH} 4 \mathrm{OH}) 25 \%$ purity, NaNO3 99\% purity.

\subsection{Preparation of MCM-41}

MCM-41 was incorporated by utilizing the accompanying system detailed by [12] with a few changes. CTAB was added to deionize $\mathrm{H} 2 \mathrm{O}$ under mixing. Ammonia solution was added to the framework when the arrangement turned clear, and it was permitted to blend for $5 \mathrm{~min}$. From that point forward, TEOS was added quickly under blending for $3 \mathrm{~h}$ at room temperature. The MCM-41 was recuperated by filtration and

dehydrated at ambient temperature all-night. The CTAB was evacuated by calcining the MCM- 41 at $540^{\circ} \mathrm{C}$ for $9 \mathrm{~h}$.

\subsection{Functionalization of MCM-41}

The MCM-41 was functionalized with mono-amine utilizing post-grafting technique [31]. Amount of calcined MCM-41 was refluxed in dry toluene containing 3aminopropyltriethoxysilane (TEOS/APTES molar proportion $=1 / 10$ ) under vigorous mixing at $110^{\circ} \mathrm{C}$ for 8 h. After that the functionalized MCM-41 were gathered by filtration, cleansed a couple of times with ethanol lastly dehydrated at $100^{\circ} \mathrm{C}$. Prior to any adsorption test, the NH2MCM-41 was acidified with $\mathrm{HCl}$ in order to change over the amino gatherings (- NH2) into ammonium moieties ($\mathrm{NH} 3+)$ which are in charge of the adsorption of anions [32]. After acidification MCM-41 was recouped by filtration, dried at ambient temperature overnight before it utilize as sorbent material.

\section{Characterizations}

X-beam powder diffraction (XRD) tests were done with a diffraction unit [Type: Shimadzu-6000, Origin: Japan]. Morphology analysis of MCM-41 was performed using SEM instrument [Type: VEGA 3 LM, Origin: Germany]. The specified surface area and the total pore volume of MCM-41 were studied by (Brunauer, Emmett and Teller) analyzer [Type: Q-surf 9600, Origin: USA]. FT-IR spectra were read in the scope of $400-4000 \mathrm{~cm}-1$ by employing a FT-IR spectrophotometer [Type: Bruker -Tensor 27, Origin: Germany]. A thermogravimetric analysis (TGA) was executed using thermogravimetric analyzer TG-DSC [Type: STA PT1000, origin: USA].

\section{Batch Adsorption Studies}

Batch adsorption tests were done in $150 \mathrm{ml}$ funnel flasks containing $100 \mathrm{ml}$ of nitrate solution of known focus and $\mathrm{pH}$. A known measure of adsorbent was included the flasks at room temperature. The blend was mixed on electrical shaker [Type: Unimax 1010 DT Heidolph, Origin: Germany] at certain speed to get homogenous blend. The mixture was examined by taking the sample from the shaker at standard interims of time. In each sample, the adsorbent was isolated by centrifuge [Type: PLC-03, Origin: Gemmy Industrial Corp. - Taiwan] for $10 \mathrm{~min}$. what's more, separating by filtering paper [Type: Wei Kong $\mathrm{Lu} \mathrm{Mo,} 0.22 \mu \times 100$ circles, Origin: China]. The absorbance of the supported solution was evaluated to detect the nitrate focus. Table 1 demonstrates the scope of parameters which were considered.

Table 1: Range of parameters that were studied for adsorption of Nitrate anion by MCM-41.

\begin{tabular}{|c|c|c|c|}
\hline Adsorbent & parameters & range & unit \\
\hline MCM-41 & $\begin{array}{c}\text { contact time } \\
\text { adsorbent } \\
\text { dose } \\
\text { initial conc. } \\
\text { of } \mathrm{NO}_{3} \text { ion } \\
\mathrm{pH}\end{array}$ & $(0-140)$ & $\mathrm{min}$. \\
& $\begin{array}{c}(25-150) \\
\text { temperature }\end{array}$ & $\mathrm{g} / \mathrm{L}$ \\
$(2-11)$ & \\
\hline
\end{tabular}

The adsorption capacity qt was computed by condition (1) and the removal efficiency was figured by condition (2):

$$
\begin{aligned}
& \mathrm{qt}=\left(\mathrm{C}_{\mathrm{o}}-\mathrm{Ce}\right) \mathrm{V} / \mathrm{W} \\
& \text { Removal } \%=\left[\left(\mathrm{C}_{\mathrm{o}} \mathrm{Ce}\right) /\left(\mathrm{C}_{\mathrm{o}}\right)\right] x 100 \%
\end{aligned}
$$

Where: qt adsorption limit at time $\mathrm{t}(\mathrm{mg} / \mathrm{g}), \mathrm{V}$ volume of NO3 anion arrangement (L), Co initial focus of NO3 anion arrangement (mg/l), $\mathrm{Ct}$ focus of NO3 anion arrangement at time $\mathrm{t}(\mathrm{mg} / \mathrm{l})$, and $\mathrm{W}$ mass of MCM-41(g).

The Langmuir isotherm expects that adsorption happens when a free adsorbate atom slams into an abandoned adsorption site and each adsorbed particle has a similar rate to desorption [16]. The model can be composed as:

$$
\mathrm{qe} \square \square\left(\mathrm{q} \_\mathrm{m} \text { K_L C_e }\right) /\left(1+\mathrm{K} \_\mathrm{L} \text { C_e }\right)
$$

Where: qm Langmuir constant relating to adsorption limit $\mathrm{mg} / \mathrm{g}$ and $\mathrm{KL}$ consistent that alludes to energy of adsorption L/mg. A dimensionless steady, usually known as separation factor or balance parameter (RL) characterized by Webber and Chakkravorti [30] can be written as:

$$
\mathrm{RL}=1 /\left(1+\mathrm{bC}_{\mathrm{o}}\right)
$$

Where: Co $(\mathrm{mg} / \mathrm{L})$ is the adsorbate initial concentration. The estimation of RL demonstrates how good the isotherm is, as appeared in Table 2 
Table 2: Kind of isotherm as indicated by estimation of RL.

\begin{tabular}{|c|c|}
\hline Estimation of RL & Kind of Isotherm \\
\hline $0<\mathrm{RL}<1$ & Favorable \\
\hline $\mathrm{RL}>1$ & Unfavorable \\
\hline $\mathrm{RL}=1$ & Linear \\
\hline $\mathrm{RL}=0$ & Irreversible \\
\hline
\end{tabular}

Another most generally utilized model is the Freundlich isotherm. The Freundlich isotherm is communicated as:

$q e=K f \operatorname{Ce} 1 / n$

Where: $\mathrm{Kf}$ and $1 / \mathrm{n}$ are Freundlich constants identified with adsorption capacity and adsorption intensity, separately of the sorbent. Temkin and Pyzhev considered the effects of some indirect sorbate/ adsorbate interactions on adsorption isotherms and suggested that because of these interactions the heat of adsorption of all the molecules in the layer would decrease linearly with coverage [27]. The Temkin isotherm has been utilized as a part of the accompanying structure:

$$
\mathrm{q} \_\mathrm{e}=\left(\mathrm{R} \_\mathrm{e} T\right) / \mathrm{b} \ln \quad\left(\mathrm{K}_{-} \mathrm{t} \text { C_e }\right)
$$

Where: Re: The general gas constant $(8.314 \mathrm{~J} / \mathrm{mol} \mathrm{K}), \mathrm{b}$ : Related to heat of adsorption $(\mathrm{J} / \mathrm{mol}), \mathrm{T}$ : The temperature $(\mathrm{K}), \mathrm{Kt}$ : The equilibrium binding consistent $(\mathrm{L} / \mathrm{mg})$ comparing to the most extreme binding energy.

The adsorption energy can be portrayed by a pseudo-first request condition [15].

$$
\log \left(q \_t-q \_e\right)=\log \quad \text { [q_e-k_1ads/2.303》t }
$$

Where: qt is the capacity of adsorption at time $\mathrm{t}$ in $(\mathrm{mg} / \mathrm{g})$, klads: The rate constant of the pseudo-first order model in (min-1). The pseudo-second order equation [14] can be written as:

$$
\mathrm{t} / \mathrm{q} \_\mathrm{t}=1 /\left(\mathrm{k} \_2 \mathrm{ads} \llbracket \mathrm{q} \rrbracket \_\mathrm{e}^{2}\right)+\left(1 / \mathrm{q} \_\mathrm{e}\right) \mathrm{t}
$$

Where: k2ads: The rate constant of the pseudo-second order in ( $\mathrm{g} / \mathrm{mg}$. min). Thermodynamics information, for example, Gibbs free vitality $\left(\Delta \mathrm{G}^{\circ}\right)$, enthalpy $\left(\Delta \mathrm{H}^{\circ}\right)$, and entropy $\left(\Delta \mathrm{S}^{\circ}\right)$, were resolved from traditional direct type of Van't Hoff condition (9):

$$
\ln \mathrm{Kd}=-\left(\Delta \mathrm{H}^{\circ}\right) / \mathrm{RT}+\left(\Delta \mathrm{S}^{\circ}\right) / \mathrm{R}
$$

Where: $\Delta \mathrm{H}^{\circ}$ (change in enthalpy $\left.(\mathrm{J} / \mathrm{mol})\right)$ and $\Delta \mathrm{S}^{\circ}$ (change in entropy $(\mathrm{J} / \mathrm{mol} . \mathrm{K}))$ values acquired from the incline and capture of lnkd versus $1 / \mathrm{T}$ plots. $\mathrm{T}$ is the temperature in $\mathrm{K}$; $\mathrm{R}$ is the general gas constant $(8.314 \mathrm{~J} / \mathrm{mol} \mathrm{K}) . \mathrm{Kd}$ is the distribution coefficient. The Gibbs free energy is calculated according to the following equation:

$$
\Delta \mathrm{G}^{\circ}=-\mathrm{RT} \ln \mathrm{Kd}
$$

Where: $\Delta \mathrm{G}^{\circ}$ is standard free energy change $(\mathrm{J} / \mathrm{mol})[7]$.

\section{Results and Discussion}

\section{$5.1 \quad$ Characterization of MCM-41}

Fig. 1- a, b gives the XRD patterns of our results. A diffractogram showed typical reflections between 20 and $10 \mathrm{o}$ of $2 \theta$ range [25] the XRD patterns are dominated by (100), (110), and (200) reflections, indicating the formation of well-defined hexagonal MCM-41. The observable peak at $2 \theta$ running in the region of $2^{\circ}$ and $2.5^{\circ}$ identifies with 100 plane, which is decisive of standard MCM-41 [20]. The XRD crest powers of the NH2-MCM41 are less than that of MCM-41. The decrease in peak compel gives confirm that amino-functionalized bunches happened primarily inside the mesopore channels [12].The absence of the 110 and 200 peaks in NH2-MCM-41 indicated that the mesopores of the NH2-MCM-41 were less ordered.

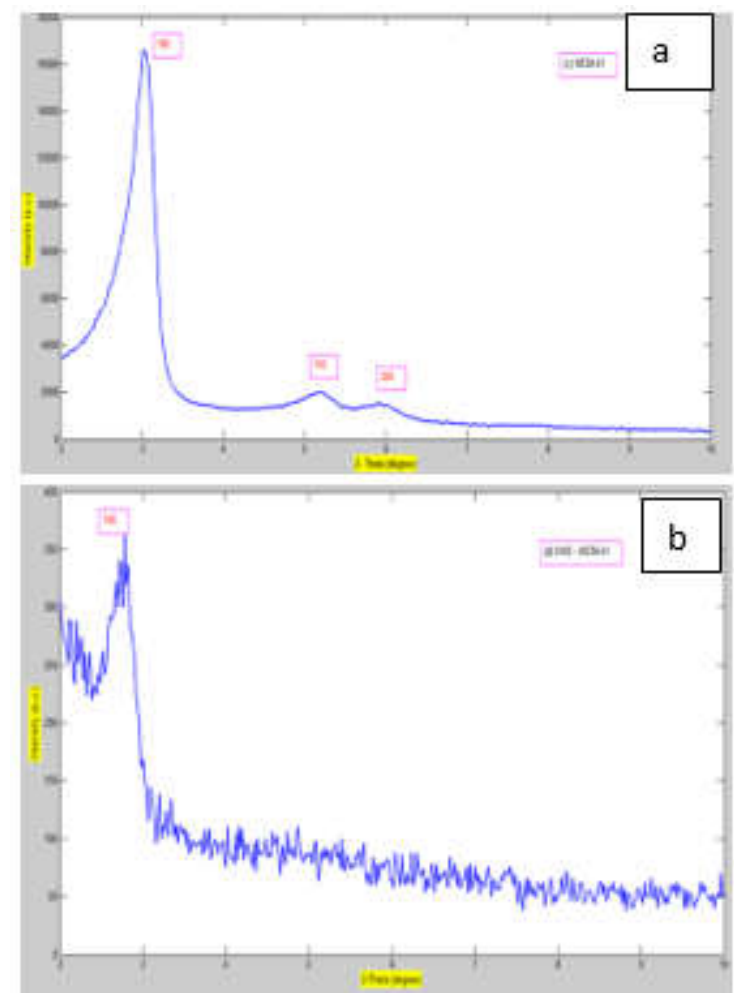

Figure 1: (a) XRD patterns of MCM-41. (b) XRD patterns of NH2-MCM-41.

Aftereffects of the N2 adsorption-desorption volumetric examination of the blended material are displayed in Table 3 . Table 3 compresses the auxiliary properties of the combined material. The pure MCM-41 test showed substantially higher BET surface area and total pore volume if contrasted with the NH2-MCM-41. This reduction in the composition variables was beforehand answered to go with the surface change of mesoporous materials with natural useful gatherings [25] and was ascribed to the control of the pore system by the terminal 
natural utilitarian gatherings distending into the inner surface of the pores.

Table 3: Physical properties before and after functionalization

\begin{tabular}{|c|c|c|}
\hline adsorbent & $\begin{array}{c}\text { Surface area } \\
(\mathrm{m} 2 / \mathrm{g})\end{array}$ & $\begin{array}{c}\text { Total pore } \\
\text { volume }(\mathrm{cm} 3 / \mathrm{g})\end{array}$ \\
\hline MCM-41 & 1492.008 & 0.0661 \\
\hline NH2-MCM-41 & 98.553 & 0.7591 \\
\hline
\end{tabular}

Fig. $2 \mathrm{a}, \mathrm{b}$ demonstrates the infrared spectra of MCM-41 preceding and following functionalized with amino gatherings. A wide retention band centered at $3100-3600$ $\mathrm{cm}-1$ resolved to hydrogen-reinforced $\mathrm{Si}-\mathrm{OH}$ bunches was barged in by physically adsorbed water. In every one of the materials, the groups around 467, 800, 1082 and $1227 \mathrm{~cm}-1$ are administered to connections of ( $\mathrm{Si}-\mathrm{O}-\mathrm{Si})$, which is related with the arrangement of a dense silica organize [30]. While a sharp assimilation is seen at 3411 cm-1 and $960 \mathrm{~cm}-1$ attributed to free $\mathrm{Si}-\mathrm{OH}$ gatherings. The nearness of groups in $692 \mathrm{~cm}-1$ and $2939 \mathrm{~cm}-1$ is allotted to $\mathrm{N}-\mathrm{H}$ twisting vibration, $\mathrm{N}-\mathrm{H}$ lopsided bowing vibration and $\mathrm{C}-\mathrm{H}$ connect, separately [18].

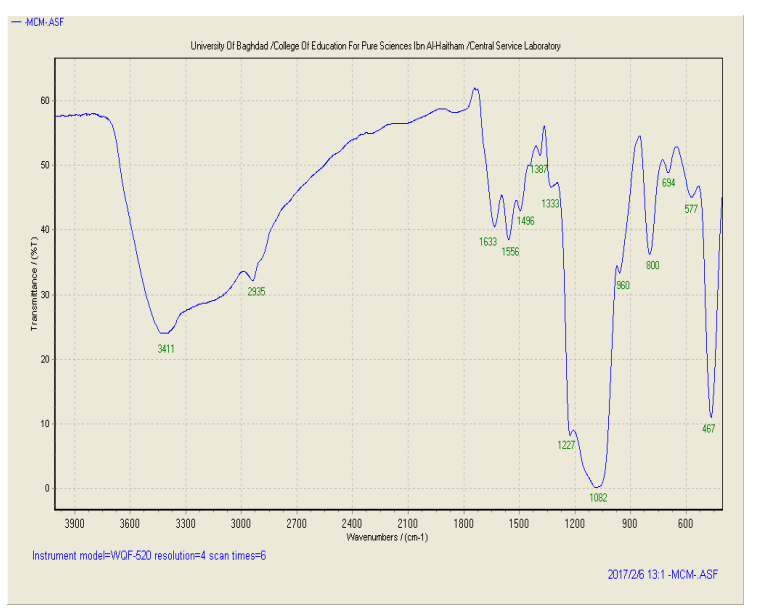

Figure 2 (a): FT-IR spectra of MCM-41

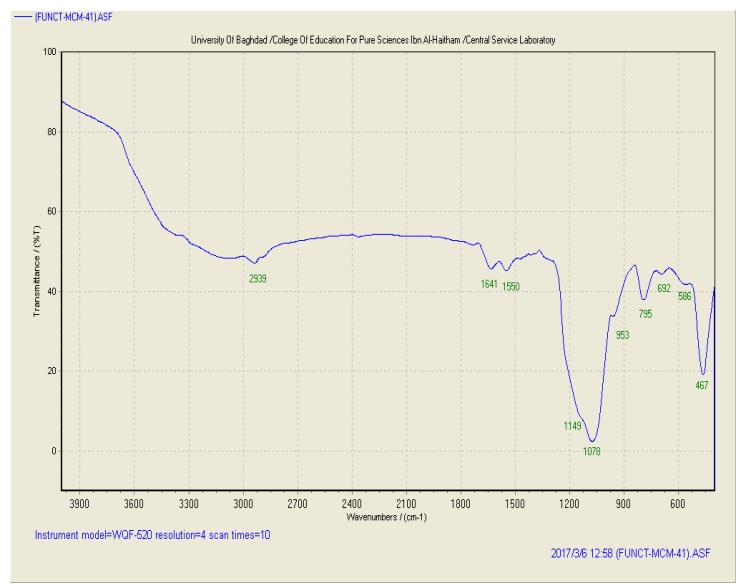

Figure 2 (b) : FT-IR spectra of NH2- MCM-41.

The organic content of the surface adjusted mesoporous NH2-MCM-41, surveyed by TGA is appeared in Fig. 3.
The NH2-MCM-41 demonstrated a high weight reduction which approaches $-15.8232 \%$. The weight reduction beneath $150^{\circ} \mathrm{C}$ compares to the desorption of water atoms and it is equivalent to $-0.7 \%$. In bends comparing to NH2MCM-41, the weight reduction at over $150^{\circ} \mathrm{C}$ is because of the disintegration of amine tied down to the pore walls [21].

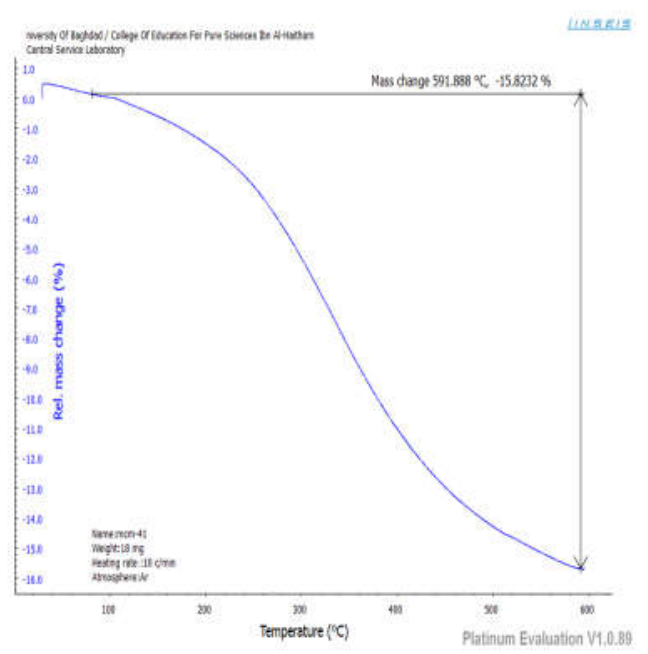

Figure 3: Thermal Gravimetric Analyses.

\subsection{Batch Adsorption Studies}

\subsubsection{Comparison between MCM-41 and NH2- MCM-41}

A near report was done between MCM-41 and NH2MCM-41 keeping in mind the end goal to research the viability of amino useful gathering on adsorption of nitrate anion particle from its fluid arrangement and the outcomes are appeared in Fig.4. This figure demonstrates that MCM41 has frail partiality to adsorb nitrate anion, while the removal efficiency of nitrate anion has been expanded after the functionalization of MCM-41 with amino gathering $(\mathrm{NH} 2)$.

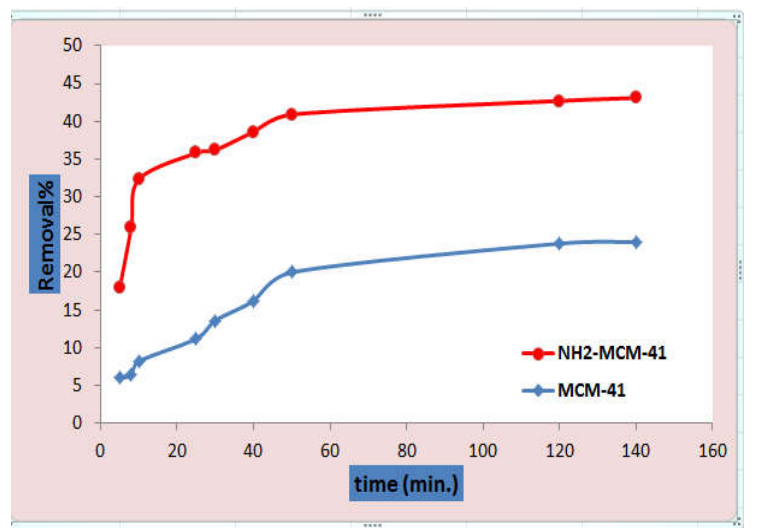

Figure 4: Comparison between MCM-41 and NH2MCM-41 
A comparison between MCM-41, NH2-MCM-41 and acidified NH2-MCM-41 was made as shown in Fig.5. The results showed that the acidified $\mathrm{NH} 2-\mathrm{MCM}-41$ is the best adsorbent for the removal of nitrate anion with maximum removal efficiency $43.1 \%$. For that reason acidified NH2MCM-41 was used in this study

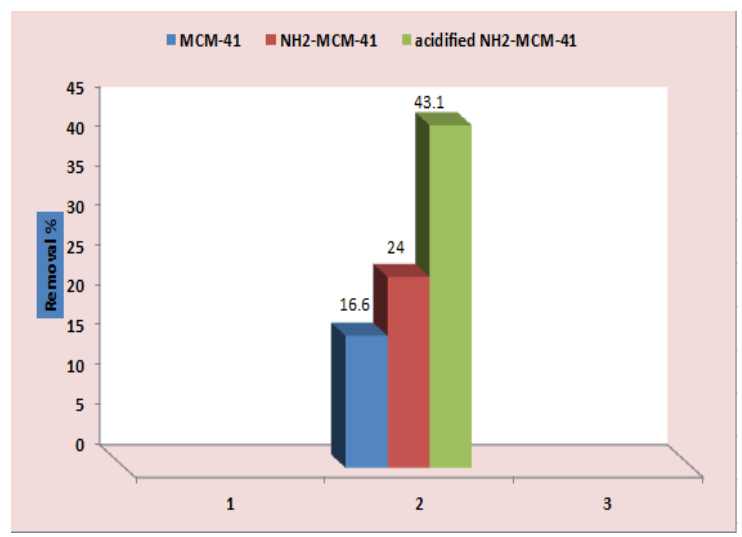

Figure 5: Comparison between MCM-41, NH2-MCM-41 and acidified NH2-MCM-41.

\subsubsection{Effect of Contact Time}

The relationship between contact time and the removal of nitrate anion on NH2-MCM-41 is shown in Fig.6

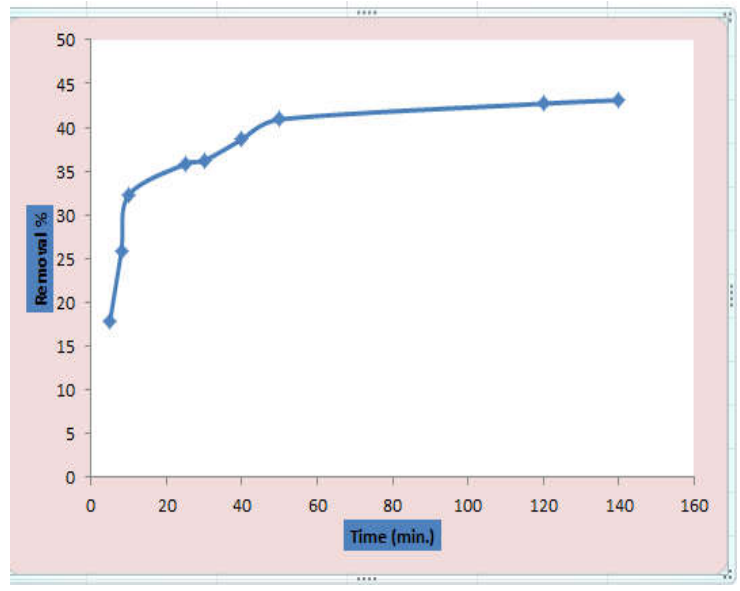

Figure 6: Effect of contact time on the removal efficiency of nitrate anion $(\mathrm{Co}=50 \mathrm{mg} / \mathrm{L}$, at room temperature, and adsorbent dose $=0.1 \mathrm{~g}$ ).

This figure shows that by increasing contact time, the NO3 anion particles have a more extended residence time for adsorption on the adsorbent surface area. At balance, the surface of the adsorbent was covered with NO3 anions; subsequently a more blending time does not extend NO3 anion removal $\%$ from wastewater.

\subsubsection{Effect of Adsorbent Dose}

The effect of the adsorbent dose on the removal efficiency of nitrate anions is shown in Fig.7. It was noticed that the removal\% of $\mathrm{NO} 3$ onto $\mathrm{NH} 2-\mathrm{MCM}-41$ increased quickly with the expansion of adsorbent dose. This outcome is normal on the grounds that the expansion of adsorbent dosage prompts more surface zone. At the point when the adsorbent measurements was expanded from $0.1 \mathrm{~g}$ to $1.7 \mathrm{~g}$, the level of NO3 particles adsorption expanded from 23.2 to $81 \%$. Hence, $1.7 \mathrm{~g} / 100 \mathrm{~mL}$ was considered as ideal dosage and was utilized for additionally examine

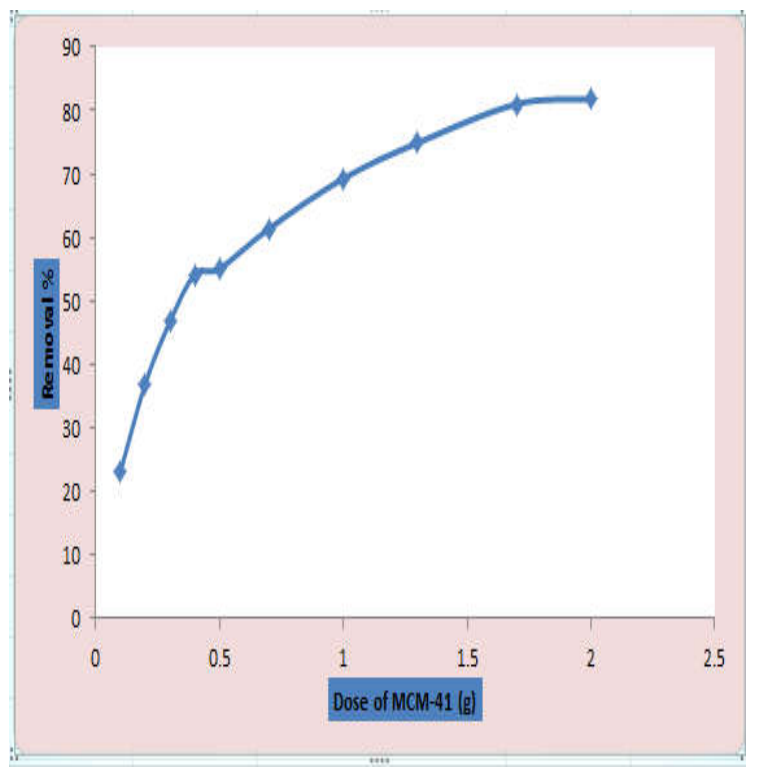

Figure 7: Effect of adsorbent dose on the removal efficiency of nitrate anion $(\mathrm{Co}=50 \mathrm{mg} / \mathrm{L}$, at room temperature).

\subsubsection{Effect of Initial Concentration of $\mathrm{NO3}$ anion}

The effect of initial concentration of NO3 anion on adsorption behavior was explored. The results shown in Fig. 8 revealed that the evacuation productivity diminishes as the initial concentration of NO3 increments. This can be clarified in view of the way that the adsorbent has predetermined number of dynamic destinations, which would wind up plainly immersed over a specific NO3 particle focus.

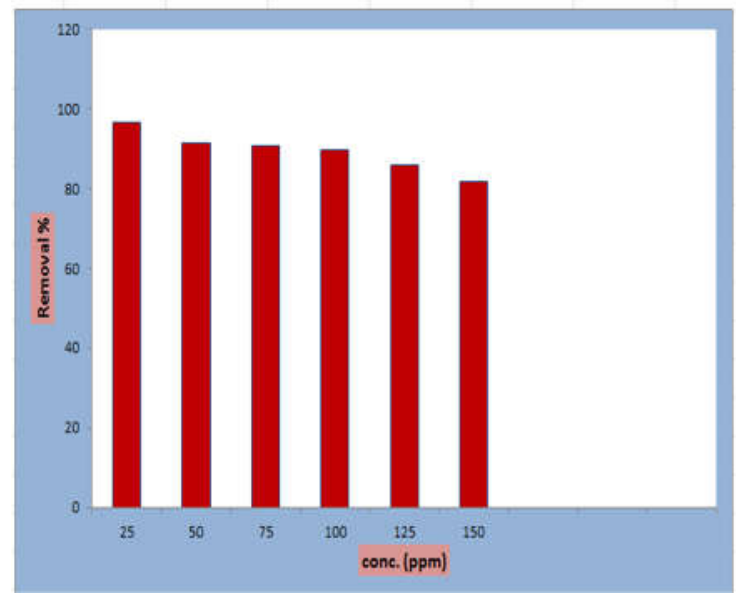


Figure 8: Effect of initial concentration of $\mathrm{NO} 3$ anion on the removal $\%$ (time $=120 \mathrm{~min}$., dose of NH2- MCM$41=1.7 \mathrm{~g}$, at room temperature).

\subsubsection{Effect of $\mathrm{PH}$}

The $\mathrm{pH}$ is an essential variable impacting the adsorption procedure. The removal of nitrate from aqueous solution utilizing NH2-MCM-41 was researched at $\mathrm{pH}$ scope of 211 and the outcomes got were represented in the Fig.9 The removal efficiency expanded by raising the $\mathrm{pH}$ values, Therefore, at bring down $\mathrm{pH}$ values comparing to expanding sharpness destinations; the arrangement gives more protons prompting ammonium moieties fit for drawing in anionic species (nitrate anions) by electrostatic powers. At the inverse, at higher $\mathrm{pH}$ esteems, the arrangement gives more hydroxide (OH-) bunches so the surface charged of ammonium functionalized MCM-41 ends up plainly impartial and loses electrostatic connection for the anionic species [29].

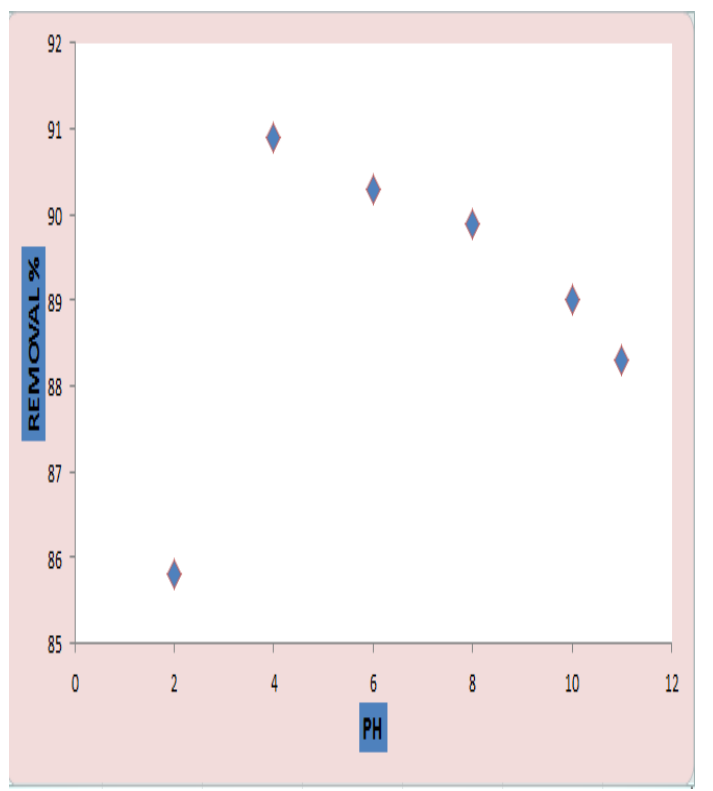

Figure 9: Effect of $\mathrm{PH}$ on the removal\%.

\subsubsection{Effect of temperature}

To evaluate the impact of temperature on NO3 ion adsorption by NH2-MCM-41 was studied at (297, 313, and 333$){ }^{\circ} \mathrm{K}$ with different initial concentration (25-150 $\mathrm{mg} / \mathrm{L}$ ). The results are presented in Fig. $10 \mathrm{a}, \mathrm{b}$. It has been determined that the maximum adsorption capacity of these samples and the amount of nitrate anions removed from aqueous solution at equilibrium decreased by rising temperature from $297^{\circ} \mathrm{K}$ to $333 \mathrm{~K}^{\circ}$. From Fig. 10 a, it is determined that the amount of nitrate ions removed from aqueous solution at equilibrium decreased from $96.6 \%$ to $59.9 \%$ by rising temperature from $297^{\circ} \mathrm{K}$ to $333^{\circ} \mathrm{K}$ with initial concentration of $25 \mathrm{mg} / \mathrm{l}$. This result also indicates the exothermic character of the adsorption method.

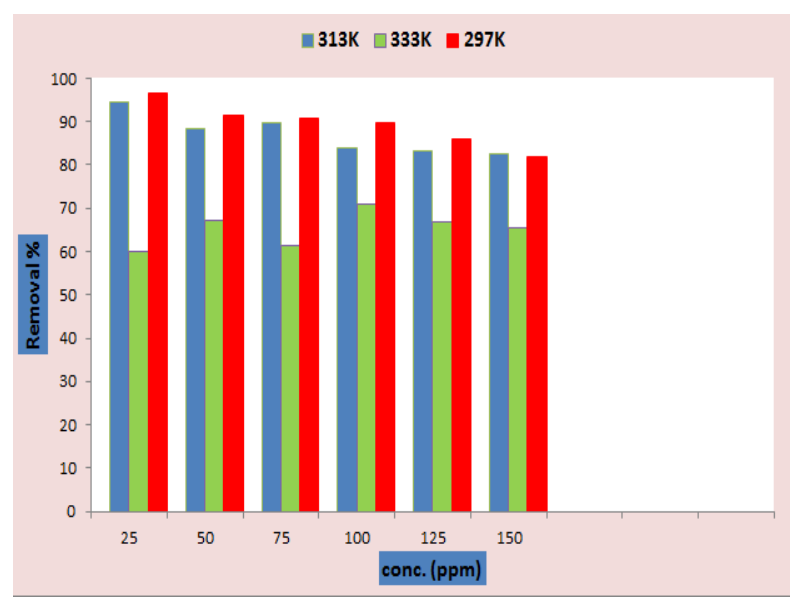

Figure 10 (a): Effect of temperature on $\mathrm{NO}_{3}$ anion removal with different initial concentrations.

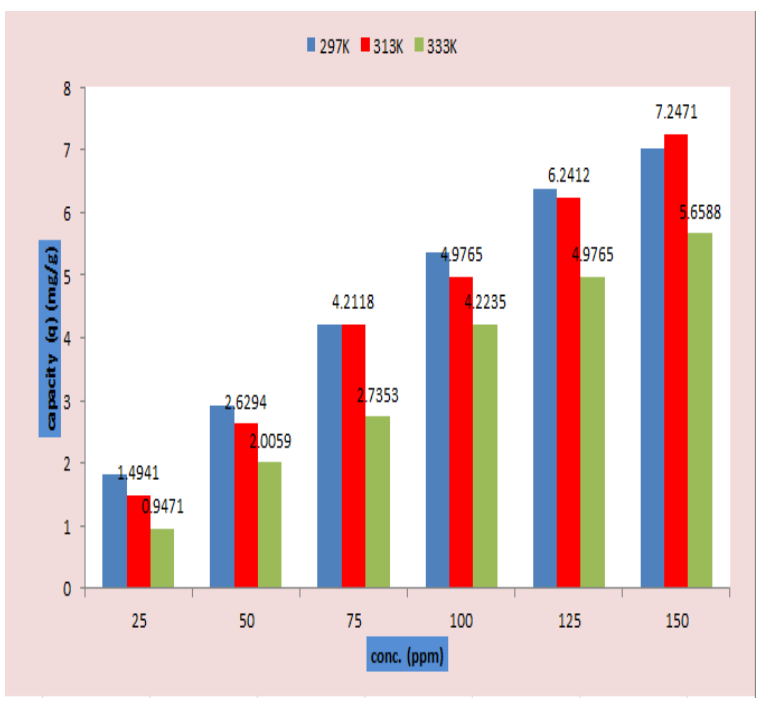

Figure 10 (b): Effect of temperature on NO3 anion capacity with different initial concentrations (time=120min, NH2-MCM-41 dose $=1.7 \mathrm{~g}$ ).

\subsubsection{Comparison between MCM-41 and Different Adsorbents}

Fig.11 shows a comparative between MCM-41 and different adsorbents (MCM-48, SBA-15 and activated carbon) used so as to explore the potency of MCM-41 on adsorption of NO3 anion. This figure shows that MCM-41 was the best adsorbent, while the percentage removal of NO3 has been decreased with time when the other adsorbents were used (MCM-48, SBA-15 and activated carbon). 


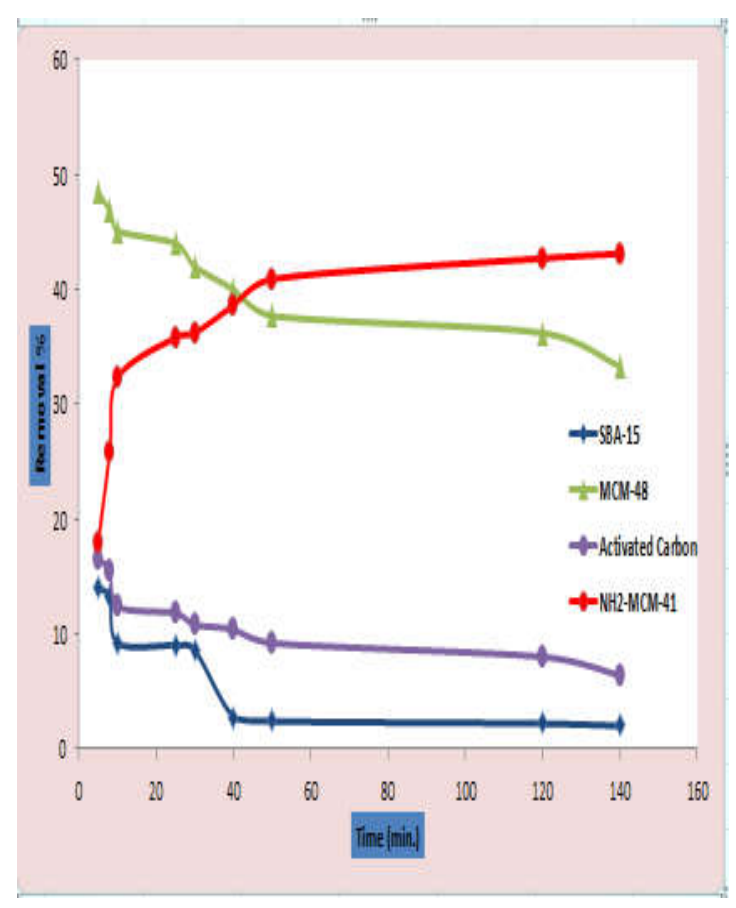

Figure 11: Comparison between MCM-41 and different adsorbents $(\mathrm{Co}=50 \mathrm{ppm}$, time $=120 \mathrm{~min}$., dose of adsorbent $=0.1 \mathrm{~g}$, at room temp.)

\section{Adsorption Isotherms}

Adsorption isotherms are scientific models that depict the appropriation of the adsorbate species among solid and fluid phases, and are major information to recognize the system of the adsorption. The Langmuir, Freundlich and Temkin models are the most often utilized models. In this examination, these models were utilized to depict the connection between the adsorbed sum of nitrate particles on NH2-MCM-41 and its equilibrium focus in solution [20]. The b, qm, n, Kf, B and Kt esteems and the nonlinear reversion coefficient of resolution (R2) for Langmuir, Freundlich and Temkin isotherms are given in Table 4. The coefficient of resolution shows that adsorption was fitted better by the Freundlich isotherm.

Table 4 : Model parameters for NO3 anion adsorption on NH2-MCM-4.

\begin{tabular}{|c|c|c|c|}
\hline $\begin{array}{c}\text { Isotherm } \\
\text { model }\end{array}$ & $297 \mathrm{~K}$ & $313 \mathrm{~K}$ & $333 \mathrm{~K}$ \\
\hline $\begin{array}{c}\text { Langmuir: } \\
\text { qmax(mg/g) }\end{array}$ & 18.94 & 34.84 & 17.66 \\
\hline $\mathrm{b}(\mathrm{L} / \mathrm{mg})$ & $\begin{array}{c}3.9284^{*} 10 \\
-3\end{array}$ & $\begin{array}{c}1.7346^{*} 10 \\
-3\end{array}$ & $\begin{array}{c}3.1415^{*} 10 \\
-3\end{array}$ \\
\hline $\mathrm{R} 2$ & 0.9204 & 0.7738 & 0.9999 \\
\hline $\mathrm{RL}$ & 0.8 & 0.9 & 0.9 \\
\hline
\end{tabular}

\begin{tabular}{|c|c|c|c|}
\hline $\begin{array}{c}\text { Freundlich: } \\
\text { Kf(mg1-ng- } \\
1 \\
\text { Ln) }\end{array}$ & 0.1458 & 0.0845 & 0.0366 \\
\hline $1 / \mathrm{n}$ & 0.7777 & 0.8899 & 1.0141 \\
\hline $\mathrm{R} 2$ & 0.9967 & 0.9960 & 0.9940 \\
\hline $\begin{array}{c}\text { Temkin: } \\
\mathrm{B}(\mathrm{J} / \mathrm{mol})\end{array}$ & 2.9818 & 3.1843 & 2.6729 \\
\hline $\mathrm{Kt}(\mathrm{L} / \mathrm{g})$ & 0.0628 & 0.0543 & 0.0481 \\
\hline $\mathrm{R} 2$ & 0.9592 & 0.9507 & 0.9413 \\
\hline
\end{tabular}

The studied most extreme adsorption limit (qmax) expanded from 18.94 to $34.84 \mathrm{mg} / \mathrm{g}$ for an expansion in the arrangement temperatures from $297 \mathrm{~K}$ to $313 \mathrm{~K}$; the fundamental reason could be that chemisorption, being a chemical procedure, often requires more power. Also, high temperature gave more opportunities to NO3 anions to pass the external boundary layer, and develop the expansion of pore volume and surface area allowing NO3 anions to enter further. Keeping in mind the end goal to expect the appropriate of an adsorption method, the Langmuir condition can also be communicated as far as a dimensionless separation factor or an equilibrium parameter RL, Table 4 demonstrates the RL esteems in light of the Langmuir isotherm display, in which all RL esteems are more than 0 yet under 1 showing that the adsorption of NO3 anion is favorable.

\section{Adsorption Thermodynamics}

To examine the thermodynamics of adsorption of NO3 on NH2-MCM-41, thermodynamic constants such as enthalpy change $\Delta \mathrm{H}^{\circ}$, free energy change $\Delta \mathrm{G}^{\circ}$ and entropy change $\Delta S^{\circ}$ were ascertained utilizing equations (9) and (10). The estimations of these parameters are given in Table 5. The plot of $\operatorname{lnKd}$ versus $1 / \mathrm{T}$ gives a straight line whose slope is equal to $-\Delta \mathrm{H}^{\circ} / \mathrm{R}$. Thus, $\Delta \mathrm{H}^{\circ}$ and $\Delta \mathrm{S}^{\circ}$ values were calculated from the slope and intercept of linear of $1 / \mathrm{T}$ versus $\operatorname{lnKd}$ as revealed in Fig.11.The negative estimations of $\Delta \mathrm{G}^{\circ}$ are acquired in all cases, reporting that the adsorption of nitrate onto $\mathrm{NH} 2-\mathrm{MCM}-41$ is practical and unconstrained thermodynamically. The negative estimation of $\Delta \mathrm{H}^{\circ}$ demonstrates that the adsorption of nitrate on NH2-MCM-41 is an exothermic procedure. The negative value of $\Delta \mathrm{S}^{\circ}$ shows the decreased randomness at the solid/solution interface during the adsorption process of nitrate onto NH2-MCM-41. 


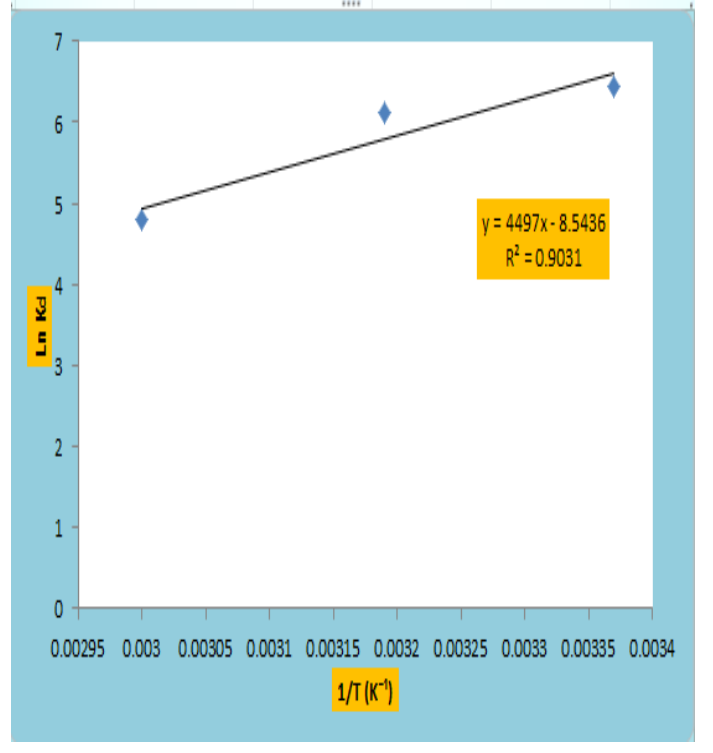

Figure 11: Van't Hoff plot for NO3 anion adsorption on $\mathrm{NH} 2-\mathrm{MCM}-41(\mathrm{Co}=50 \mathrm{mg} / \mathrm{L}, \mathrm{pH}=4$, dose $=1.7 \mathrm{~g}$, time $=120 \mathrm{~min}$ ).

Table 5: Thermodynamic properties of NO3 anion adsorption on NH2-MCM-41.

\begin{tabular}{|c|c|c|c|}
\hline $\begin{array}{c}\text { Temp. } \\
(\mathrm{K})\end{array}$ & $\begin{array}{c}\Delta \mathrm{H}^{\mathrm{o}} \\
(\mathrm{kJ} / \mathrm{mol})\end{array}$ & $\begin{array}{c}\Delta \mathrm{S}^{\mathrm{o}} \\
(\mathrm{kJ} / \mathrm{mol} . \mathrm{K})\end{array}$ & $\begin{array}{c}\Delta \mathrm{G}^{\mathrm{o}} \\
(\mathrm{kJ} / \mathrm{mol})\end{array}$ \\
\cline { 1 - 1 } 297 & \multirow{3}{*}{-37.39} & -0.0710 & -15.93 \\
\cline { 1 - 1 } \cline { 4 - 4 } & & & -15.92 \\
\hline 313 & & & -13.27 \\
\hline
\end{tabular}

\section{Adsorption Kinetic Study}

The adsorption kinetic investigation has a critical part in the treatment of wastewater as it gives important data on the pathways and system of adsorption responses. The kinetics of nitrate sorption on NH2-MCM-41 was examined utilizing pseudo-first-order and pseudo-secondorder kinetic models. The best-fit model was chosen in view of the match between exploratory qe (exp.) and theoretical qe (cal.) intake values and straight relationship coefficient (R2) values at two contemplated fixations. The gains acquired by pseudo-second-order were observed to be in good concurrence with exploratory information and can be utilized to positively clarify the nitrate sorption on NH2-MCM-41. The active parameters of the two models are exhibited in Table 6.

\section{Effect of competitive species on the adsorption of nitrate}

In the present work, the majority of the tests were finished with just nitrate anions yet in the natural system; a few different particles are
Table 6: parameters obtained using pseudo-first and second order.

\begin{tabular}{|c|c|c|}
\hline \multicolumn{2}{|c|}{ Adsorbent } & $\mathrm{NH}_{2}$-MCM41 \\
\hline \multicolumn{2}{|c|}{$\mathrm{q}_{\mathrm{e} \text { (exp.) }}(\mathrm{mg} / \mathrm{g})$} & 2.594 \\
\hline \multirow{2}{*}{$\begin{array}{c}\text { pseudo- } \\
\text { first-order }\end{array}$} & $\mathrm{q}_{\mathrm{e}(\mathrm{cal} .)}(\mathrm{mg} / \mathrm{g})$ & 0.108 \\
\cline { 2 - 3 } & $\mathrm{k}_{\text {lads }}\left(\mathrm{min}^{-1}\right)$ & 0.029 \\
\cline { 2 - 3 } & $\mathrm{R}^{2}$ & 0.924 \\
\hline \multirow{2}{*}{$\begin{array}{c}\text { Pseudo- } \\
\text { second- } \\
\text { order }\end{array}$} & $\mathrm{q}_{\mathrm{e}(\mathrm{cal} .}(\mathrm{mg} / \mathrm{g})$ & 2.59 \\
\cline { 2 - 3 } & $\mathrm{k}_{\text {2ads }}(\mathrm{g} / \mathrm{mg} . \mathrm{min}$ & 1.075 \\
\cline { 2 - 3 } & $\mathrm{R}^{2}$ & 1 \\
\hline
\end{tabular}

available which can contend with nitrate. The impact of the existence of competitive anions (SO42-, CO32-, and Cl-) was researched. The outcomes are delineated in Fig.12. The decreasing of nitrate adsorbed sum within the sight of sulfate and carbonate anions, can be credited to competition between SO42- ion and CO32- ion with NO3in the surface of NH2-MCM-41 because of the reduction in the adsorption limit towards nitrate anions. Also, these outcomes are demonstrated that NH2-MCM-41 could be good material for SO42- ion and CO32- ion expulsion. Besides, the adsorption limit of nitrate diminished somewhat from $69.2 \%$ to $66.1 \%$ within the sight of chloride. The impact of contending ions on nitrate adsorption by NH2-MCM-41 was found to attend this sequence $\mathrm{Cl}-<\mathrm{SO} 42-<\mathrm{CO} 32-[29]$.

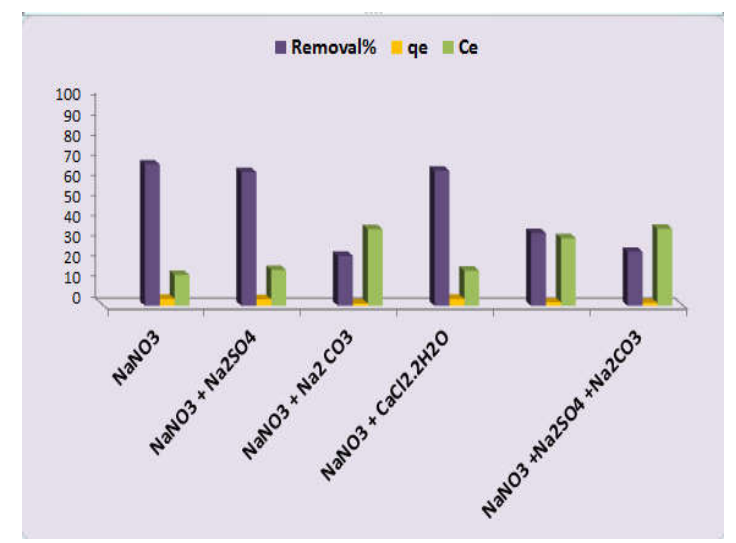

Figure 12 :The effect of the presence of other ions on nitrate adsorption.

\section{Batch Regeneration System}

Desorption and recovery researches give a thought regarding the kind of adsorption. Recovery researches were done so as to know the reusability of the NH2-MCM41. Adsorbents are generally recovered with corrosive or soluble base arrangement. In the present examination the desorption is made with $0.01 \mathrm{~mol} / \mathrm{L} \mathrm{NaOH}$. Fig. 13 demonstrates the recovered and reused consequences of NH2-MCM-41. It demonstrated that the expulsion level of 
NO3 anion declined by around $8.5 \%$ in the primary reuse for of NH2-MCM-41, and diminished a little in the following two reuses. So we conclude that NH2-MCM41 adsorbent could be reused for a few times without losing its capacity to evacuate nitrate anion, and this outcome is in concurrence with $[14,24]$.

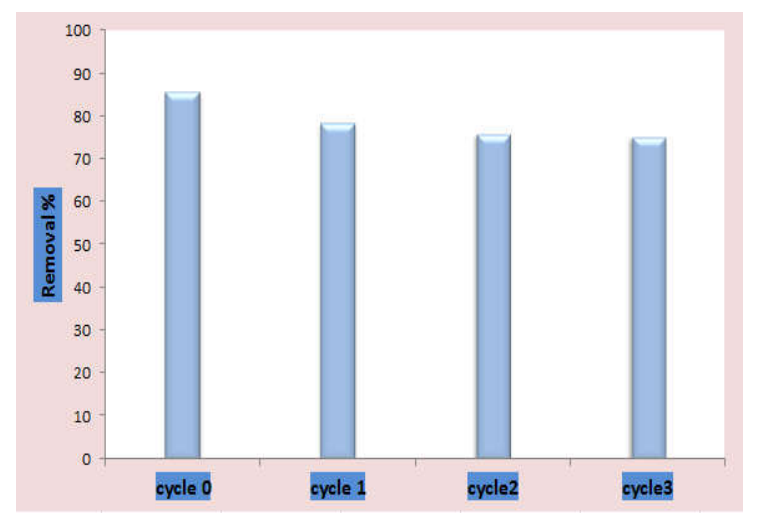

Figure 13: The reusability of $\mathrm{NH}_{2}-\mathrm{MCM}-41$ in batch experiment. $(\mathrm{pH}=4, \mathrm{Co}=50 \mathrm{mg} / \mathrm{L})$.

\section{Conclusions}

In this study, mesoporous silica MCM-41 was synthesized utilizing simple method at room temperature. The characterization results showed typical reflections between 20 and $10 \mathrm{o}$ of $2 \theta$ range and the XRD patterns are dominated by 100,110 , and 200 reflections, indicating the formation of well-defined hexagonal MCM-41 with sphere formed particles having smooth surface morphology which are regular characteristics of mesoporous materials. The outcomes demonstrate that the highest removal of nitrate was accomplished at $\mathrm{pH}$ of 4 and adsorption limit expanded with the adsorbent loading. The most extreme take-up limit with respect to nitrate anion was $17.66 \mathrm{mg} / \mathrm{g}$, for NH2-MCM-41. The kinetics of nitrate anion adsorption onto NH2-MCM-41 displayed that adsorption attractively obeys the pseudo-second-arrange condition. Desorption was quick and it was totally accomplished inside $10 \mathrm{~min}$ for nitrate anion utilizing $\mathrm{NaOH}$ at $0.01 \mathrm{M}$.

\section{References}

1- Abe K, Imamaki A, Hirano M. Removal of nitrate, nitrite, ammonium and phosphate ions from water by the aerial microalga Trentepohlia aurea. Journal of Applied Phycology 2002; $14: 129-34$.

2- Archna Sharma SK, Sobti RC. Nitrate Removal from Ground Water: A Review. E-Journal of Chemistry 2012;9:1667-75.

3- Bhatnagar A, Ji M, Choi Y, Jung W, Lee S, Kim $\mathrm{S}$, et al. Removal of Nitrate from Water by Adsorption onto Zinc Chloride Treated Activated Carbon. . Separation Science and Technology 2008; 43: 886-907.
4- Budi Hartono S QS, Jack K, Ladewig BP, Hao Z, Lu G Improving adsorbent properties of cage-like ordered amine functionalized mesoporous silica with very large pores for bio adsorption. Langmuir.2009; 25(11):6413-24.

5- Cengeloglu YT, A.; Ersoz, M.; Arslan, G. . Removal of nitrate from aqueous solution by using red mud. . Separation and Purification Technology 2006;51:374-8.

6- Chatterjee S, et al. (2009), a simple and robust algorithm for microarray data clustering based on gene population-variance ratio metric. Biotechnol J 4(9):1357-61.

7- Cheraghali RT, H. and Sepehrian, H. Preparation, characterization and lead sorption performance of alginate-SBA-15 composite as a novel adsorbent. Scientia Iranica F. 2013;20(3):1028-

8- Cloern; James \& D Jassby; Alan \& Thompson; Janet \& Hieb; Kathryn. (2007), A cold phase of the East Pacific triggers new phytoplankton blooms in San Francisco Bay. Proceedings of the National Academy of Sciences of the United States of America. 104. 18561-5. 10.

9- D. Bougard NB, P. Dabert, J.P. Delgenes and J.P. Steyer. Influence of closed loop control on microbial diversity in a nitrification process. Water Science \& Technology. 2006; 53(4):85-93.

10- Elmidaoui AE, F.; Sahli M.A.M.; Chay, L.; Elabbassi, E.; Hafsi, M.; Largeteau. D. Pollution of nitrate in Moroccan ground water: removal by electrodialysis. Desalination 2001; 136:325-32.

11- Freundlich H. Colloid and capillary Chemistry. 1926; 3(12):1454.

12- Gatkash M. Ebrahimi HY, Afsaneh Shahbazi, Ava Heidari.. DOI 10.1007/s13201-015-0364-1, 2015. Amino-functionalized mesoporous MCM41 silica as an efficient adsorbent for water treatment: batch and fixed-bed column adsorption of the nitrate anion. Appl Water Sci,. 2015;7(4):1887-901.

13- H.I. Mele'ndez-Ortiz LAG-C, Y. OlivaresMaldonado, G. Castruita, J.A. Mercado-Silva, Y.A. Perera-Mercado. . . Preparation of spherical MCM-41 molecular sieve at room temperature: Influence of the synthesis conditions in the structural properties. Ceramics International. 2012; 38:6353-8.

14- Hamoudi S SR, Belkacemi K Adsorptive removal of phosphate and nitrate anions from aqueous solutions using ammonium-functionalized mesoporous silica. Ind Eng. Chem Res. 2007; 46(25):8806-12. 
15- Ho YaMG. Pseudo-second order model for sorption processes. Process Biochemistry. 1999;34:451-65.

16- Lagergren substances", Kungliga Svenska 16Vetenskapsakademiens. Handlingar, volume 24, Issue 4, pp.1-39.

17- Langmuir I. The constitution and fundamental properties of solids and liquids. Journal of the American Chemical Society. 1916; 38(11):222195.

18- Li J MX, Hao Y, Zhao J, Sun X, Wang L Synthesis, amino-functionalization of mesoporous silica and its adsorption of Cr(VI. J Colloid Interface Sci. 2008; 312(2):309-14.

19- Maria Chong AS.; Zhao XS. (2003), Functionalization of SBA-15 with APTES and characterization of functionalized materials. J Phys Chem B 107(46):12650-12657.

20- Morghi, M.; Abidar, F.; Soudani, A.; Zerbet, M.; Chiban, M.; Kabli, H.; and Sinan, F. Removal of nitrate ions from aqueous solution using chitin as natural adsorbent. International Journal of Research in Environmental Studies. 2 (2015) 820.

21 - Parida KM, Rath D (2009) Amine functionalized MCM-41: an active and reusable catalyst for Knoevenagel condensation reaction. J Mol Catal A. Chem 310(1-2):93-100

22- Phuengprasop T, Sittiwong J, Unob F (2011) Removal of heavy metal ions by iron oxide coated sewage sludge. J Hazard Mater 186(1):502-507.

23- Rome L, Gadd GM (1987) Copper adsorption by Rhizopus arrhizus, Cladosporium resin and Penicillium italicum. Appl Microbial Biotechnol 26(1):84-90.

24- Saad, R.; Belkacemi, K.; Hamoudi, S. Adsorption of phosphate and nitrate anions on ammoniumfunctionalized MCM-48: effects of experimental conditions. Journal of colloid and interface science 2008, 311, 375-381.

25- 25- Sayari AaH, S. . Periodic Mesoporous Silica Based Organic Inorganic Nanocomposite Materials. . Chemistry of Materials. 2001;13:3151-68.

26- Schulz-Ekloff G.; Rathousky J.; and Zukal A. Controlling of morphology and characterization of pore structure of ordered mesoporous silica. Micropor mesoporous silica. Micropor Mesopore Mater. 1999; 27: 273-85.

27- Seidel, D. J., B. Sun, M. Pettey, and A. Reale. Global radiosonde balloon drift statistics. By Journal of Geophysical Research: Atmospheres (JGR) at 2011-04-07.

28- Temkin MaP, V. Kinetics of ammonia synthesis on promoted iron catalyst. Acta Phys Chim USSR. 1940;12: 327-56.

29- Thl B. Removal of nitrate from water and wastewater by ammonium- functionalized SBA16 mesoporous silica. Quebec City: Laval University; 2013.

30- Wang X, Lin KSK, Chan JCC, Cheng S (2005) direct synthesis and catalytic applications of ordered large pore amino propyl-functionalized SBA-15 mesoporous materials. J Phys Chem B 109(5):1763-1769.

31- Weber TW, Chakravorti RK. Pore and solid diffusion models for fixed-bed adsorbers. AIChE Journal. 1974; 20(2):228-38.

32- Yokoi, T.; Kubota, Y.; Tatsumi, T. Aminofunctionalized mesoporous silica as base catalyst and adsorbent. Applied Catalysis A: General 2012, 421-422, 14-37.

33- Yoshitake H. YT, Tatsumi T. Adsorption of chromate and arsenate by amino-Functionalized MCM-41 and SBA-1. Chem Mater. 2002;14:4603-10. 


\title{
تحضير ميسوبوروس سليكا (MCM-41) المعدل وأستخدامه كمادة مازة لأز الة أنيون النترات من المحاليل المائية ميوريز
}

\author{
(نعام أكرم صسبري 1، نسور صلاح عبود 2، \\ الجامعة النكنولو جية ، قسم العندسة الكبمياوية ، بغداد، العراق ، aaksabri@yahoo.com \\ الجامعة التكنولوجية،| قسم الهندسة الكيبياوية ، بغداد، العراق ، eng_noorsalah@yahoo.com

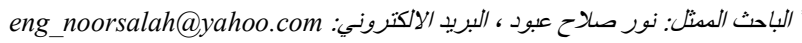 \\ نشر في: 30 حزيران 2019
}

الخلاصة - في هذه الدراسة، تم تحضير ميسوبوروس سيليكا MCM-41 في درجة حرارة الغرفة ، ثم تحميله مع مجموعة أمين عن طريق أسلوب

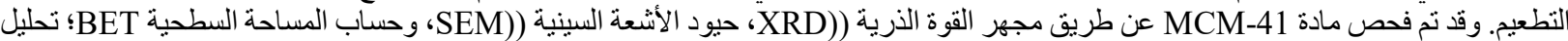

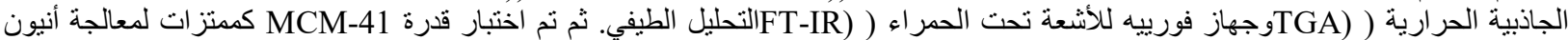

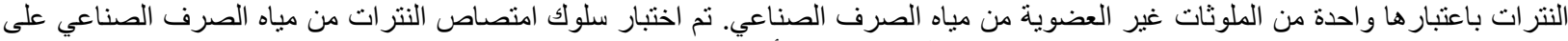

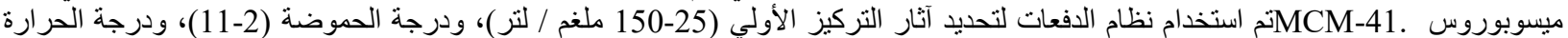

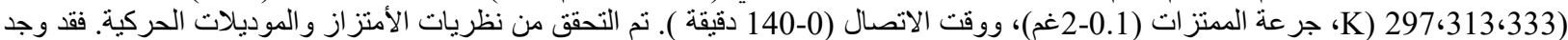
أن هذه البيانات تنطبق بشكل جيد بالنموذج الحركي . أفضل تناسب مع البيانات العملية. الكلمات الرئيسية - NH2-MCM-41،أمتصاص ، نظام الدفعات 